Emir. J. Food Agric. 2013. 25 (7): 555-561

doi: 10.9755/ejfa.v25i7.13584

http://www.ejfa.info/

\title{
AGRICULTURAL ECONOMICS
}

\section{Farming and risk attitude}

\author{
O. J. Bergfjord \\ Bergen University College, $\mathrm{Pb} 7030, \mathrm{~N}-5020$ Bergen, Norway
}

\begin{abstract}
Data from a survey among Norwegian farmers $(\mathrm{n}=514)$, combined with tax register data and data on farming area and production, are used to explore various questions related to future farming, general attitudes to farming and risk attitude. To complement the raw data, several new variables were constructed in order to compare how variables such as investment, consumption and intensity of farm production in the farmers' opinion would be affected by sudden, unexpected monetary losses and gains. These new variables say something about how various types of behavior are asymmetrically exhibited when facing unexpected gains and losses. In general, and as expected, farmers claim that a sudden gain would affect their behavior less than a sudden loss. The main exception is farm investment, which would be more affected by a sudden gain than a sudden loss would affect divestment. This is interesting, as it captures some important aspects of farming lifestyle: A sudden gain is likely to be invested in the farm, but a sudden loss would, if possible, be financed without farm divestment, as this often would lead to giving up farming, or at least some important aspects of the farming lifestyle. Overall, these results are not surprising. Nevertheless, it is argued that the results could have some interesting policy implications, both with regards to design of hedging schemes, general agricultural support schemes, and rural policy.
\end{abstract}

Key words: Farming lifestyle, Investment, Risk attitude

\section{Introduction}

The purpose of this paper is to contribute to the literature on risk attitude among farmers with insights from data on Norwegian farmers and their plans, behavior, and risk attitude. Risk attitude among farmers (for instance related to investment and operation plans) is interesting for several reasons. First, farmers are dealing with real investments, with potentially important and longterm consequences. Second, for many farmers, important decisions also have an emotional impact because the decisions will affect both future lifestyle and personal identity as a farmer - for the current and possibly future generations. Examples of such decisions include decisions to quit farming, leave the farm, or change to a different farming system. On the other hand, large investments may

Received 26 July 2012; Revised 09 November 2012; Accepted 18 November 2012; Published Online 01 May 2013

*Corresponding Author

O. J. Bergfjord

Bergen University College, Pb 7030, N-5020 Bergen, Norway

Email: ojb@hib.no be under consideration which would be likely to "lock in" the farmer and his family for a number of years.

A fundamental starting point is the relation between farm/farmer characteristics, perceptions and decisions/behavior. Several similar studies (Flaten et al., 2005; Borges and Machado, 2012) use van Raaij's (1981) model as a building block. Figure 1 below illustrates the core of this model:

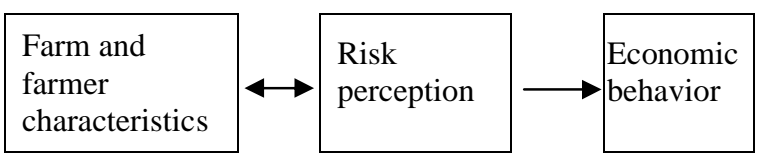

Figure 1. Van Raaij's model of a firm's decision making environment.

This model implies that different farmers will have - and state - different risk perceptions, which in turn will lead them to different decisions and different economic behavior. Hence, understanding risk perceptions in relation to differences in farm characteristics is useful with regards to understanding decisions and economic behavior.

Whereas expected utility theory traditionally has been the most commonly used model for 
decision-making under risk, a number of studies point out that this approach often fails to explain observed behavior (some classic references include Kahneman and Tversky, 1979 and Rabin and Thaler, 2001). Hence, it is even more important to understand the decision maker's frame of reference and perceptions of risk, as these often affect decisions and behavior more than "objective" considerations about expected utility (March and Shapira, 1987).

A large body of literature exists on risk and risk management in agriculture. Useful starting points are Moschini and Hennessy (2001) and Hardaker et al. (2004). In particular, Flaten et al. (2005) conducted a survey among Norwegian farmers about their risk perceptions. This literature provides a fairly good overview of the relevant risk sources and risk attitudes, both among farmers in general and Norwegian farmers in particular. Our objective in this study is more modest - to assess whether Norwegian farmers are equally risk averse in all areas, and what consequences this might have. Flaten et al. (2005) touch upon this by asking farmers to rate their willingness to take risks compared to other farmers in three areas: production, marketing, and finance and investment. The differences between the three areas seem small, with a slightly larger comparative risk aversion in the marketing area. However, this does not necessarily translate to a higher risk aversion in that area. On the other hand, similar comparative risk aversions in these three areas does not exclude the possibility that farmers as a group have very different risk attitudes in different situations, as long as each farmer perceives his own attitude compared to his peers to be similar in all three areas.

In this study, we look at (perceived) risk attitudes in several areas, and instead of comparative risk attitudes, we are concerned with how farmers would spend a large and sudden gain versus how they would finance a large and sudden loss. Our dataset only allows a proxy measure of risk aversion, but this measure fits well with earlier measurements of risk aversion, and allows us to look at differences in risk attitude in various areas, and potential consequences for policy and risk management schemes.

\section{Materials and methods}

In this paper, we utilize data from a 2008 survey among Norwegian farmers $(n=514)$, combined with tax register data and data on farming area and production, to explore various questions related to future farming, general attitudes to farming, risk aversion, and how different factors affect the utility curve of farmers.

For the development of the survey used in this study, we in part used a structure that had been used for another survey (Flaten et al., 2005; Lien et al., 2008). We also looked at questionnaires from other countries as a source of reference (e.g., Pennings and Garcia, 2001). Before the survey was conducted among the farmers, a draft questionnaire was tested, and the final questionnaire was the result of several rounds of testing.

Most questions were closed, i.e., each respondent was asked to tick one/several of a number of pre-defined alternatives. Attitudes towards listed statements were mostly measured by 7-points Likert scales, where the respondent was asked to rate his or her degree of agreement/disagreement on a scale from 1 to 7 . The final question was open, and respondents were asked to give comments in their own words. The response quality was very good, indicating that the questions were understandable and not too numerous.

The questionnaire was sent by mail to a stratified sample (with regard to age, region, and size of farms) from the Norwegian Agricultural Authority's register of farmers receiving production support. Virtually all farmers in Norway are on this register. In total, 1001 questionnaires were mailed out. Those who had not responded were sent a reminder postcard approximately four weeks later. In total, 551 responses were received. This constitutes a response rate of $56 \%$, which is satisfactory for a mail response survey. As mentioned above, the general quality of responses was very good. Nevertheless, 37 forms were incomplete and had to be rejected, thus leaving us with a total sample size of 514 .

We were able to merge the survey data on attitudes etc. with financial data obtained from the Norwegian Tax Authority. These records include both farm and off-farm income for both the farmer and partner, typically specified with regard to income source (income from farming, income from other farm-related activities, off-farm salary, and capital income/capital gain). The financial data also contained information on taxable wealth, debt etc; thus giving a reasonably good overview of the farm household's financial situation.

Finally, we also merged the two datasets from the survey and the Tax Authority with a third dataset; the Norwegian Agricultural Authority's register of farming area and production. In short, this register contains information about farmland used for different purposes, and livestock numbers. 
To study risk attitudes in different areas more carefully, some new variables were constructed in order to compare how variables such as investment, consumption and intensity of farm production in the farmers' opinion would be affected by sudden, unexpected monetary losses and gains.

To construct the new variables, we used responses to two different questions. In one question, farmers were asked to consider a situation where they won MNOK 1 (approx. \$160 000), for instance through a lottery. They were presented various opportunities to spend/invest this amount, and were asked to rate each opportunity on a scale from 1 (nothing) to 7 (everything) with regard to how much of the prize they would allocate to each opportunity. The opportunities were farm investments, investment in farm-related activities, off-farm investments, running the farm less intensively (thus probably reducing the income), work less off the farm, increase private consumption, gifts/inheritance to children, gifts to charity, pay off debt and/or bank savings, and buy shares/equity. In a related question, they were asked how they would finance a sudden loss of MNOK 1. Again, they were asked to consider various opportunities on a scale from 1 (would definitely not use) to 7 (would definitely use). The opportunities here were sale of the farm (or parts of it), increased forest harvesting, running the farm more intensively, work more off the farm, sell shares/equity, reduce private consumption, and reduce bank savings/increase loans.

A reviewer introduces a highly relevant point that risk perceptions could depend on the source of the sudden gain or loss. A sudden drop in market prices leading to a loss of $1 \mathrm{MNOK}$ does not necessarily trigger the same response as a sudden cut in subsidies leading to the same loss. However, such differences are beyond the scope of this paper to explore. In this study, the farmers were asked to consider the gain as a result of winning the lottery, and the loss as a result of losing some unspecified, unexpected legal case. Hence, both the gain and loss were framed as unexpected, unrelated to the day-to-day business of farming, and without any direct implications for future farming.

Responses to the two questions were paired, and reordered in an increasing/ordinal order from zero to six. In other words, spend/invest alternatives in case of gain were scaled from 0 (nothing) to 6 (everything), while spend/save alternatives in case of loss got a scale between 0 (would definitely not use) and 6 (would definitely use). The constructed measures of risk attitudes are illustrated in Table 1 below, and simply measure the difference between the responses to the two questions. If the value of the new variable "invest" equals 0 , this means that the average effect on investment from a sudden gain is reported to be as strong as the effect on divestment (sale of farm) from a sudden loss. If a farmer claims that a gain he would use "everything" from a gain to invest in the farm (score 6), and would "definitely not" finance a loss by sale of the farm, this would give him a score of $6-0=6$ for the new variable "invest". In short, a positive value indicates that the effect on divestment from a loss is stronger, whereas a negative value indicates that the effect on investment from a gain is stronger.

Table 1. Constructed measures of risk attitude.

\begin{tabular}{|c|c|c|c|}
\hline New variable & Variable used, gain & Variable used, loss & Interpretation, high score $(>0)$ \\
\hline Invest & Investment in farm & $\begin{array}{l}\text { Sale of farm/parts of } \\
\text { farm }\end{array}$ & $\begin{array}{l}\text { A gain means less for farm investment than a loss means for } \\
\text { giving up farming }\end{array}$ \\
\hline Intense & $\begin{array}{l}\text { Extensify farm } \\
\text { production }\end{array}$ & $\begin{array}{l}\text { Intensify farm } \\
\text { production }\end{array}$ & $\begin{array}{l}\text { A gain means more for "extensification" than a loss means } \\
\text { for "intensification" }\end{array}$ \\
\hline Off_farm & Less off-farm work & More off-farm work & $\begin{array}{l}\text { A gain means more extra off-farm work than a loss means } \\
\text { reduced off-farm work }\end{array}$ \\
\hline Consume & $\begin{array}{l}\text { More private } \\
\text { consumption }\end{array}$ & $\begin{array}{l}\text { Less private } \\
\text { consumption }\end{array}$ & $\begin{array}{l}\text { A gain means more extra private consumption than a loss } \\
\text { means reduced private consumption }\end{array}$ \\
\hline Loan & $\begin{array}{l}\text { Increase } \\
\text { savings/reduce loans }\end{array}$ & $\begin{array}{l}\text { Increase loans/use } \\
\text { savings }\end{array}$ & $\begin{array}{l}\text { A gain means more extra bank savings/reduced loans than a } \\
\text { loss means increased loans/reduced savings }\end{array}$ \\
\hline Equity & Buy shares/equity & Sell shares/equity & $\begin{array}{l}\text { A gain means more extra investments in shares/equity than a } \\
\text { loss means sales of shares/equity }\end{array}$ \\
\hline Overall & \multicolumn{2}{|c|}{ Average of all new variables } & A gain means more change in behavior than a loss \\
\hline
\end{tabular}


At this stage, it is important to emphasize how these new variables should - and shouldn't - be interpreted.

First, we know from standard expected utility (EU) theory that risk aversion implies that a monetary gain increases utility less than a loss of the same size reduces the utility. Our new measures are related to this concept, but it is not quite the standard risk aversion we are measuring. First of all, we are not concerned with the (perceived) effect on utility, but rather with the effect on behavior. Although a conceptual deviation from the standard EU framework, this is beneficial, as it is behavior we are interested in. It is, however, worth pointing out that it is known from the behavioral economics literature that a loss - or something framed as a loss - has larger consequences for behavior than a gain (see e.g. Bertrand et al. (2006) and references therein). Hence, we would expect the same tendency in our material, that (potential) losses have larger behavioral consequences than gains.

One additional weakness should be pointed out. As the questionnaire was designed for several purposes, the wording in the two questions (about gains and losses) is slightly different. Farmers were asked how large a share of a gain they would spend/invest in various areas; while they were asked how likely they were to use various sources to finance a loss. One could argue that whereas the sum of scores in the gain question should add up to $100 \%$ (or, 7 on our scale), no such relation exists in the loss question - there is nothing wrong with definitely using all the listed sources to cover the loss, and hence getting a 7 as response to all the sources.

This problem is important to be aware of, yet we will argue that it does not destroy the study. First of all, we are uncertain to what extent the respondents in fact has grasped the difference in wording. We assume that many respondents have treated the two questions in the same way, and simply ignored the difference in wording. Finally, it is worth noting that any such difference - by definition - should be identical for all the new variables. This means that no matter how much faith one has in the overall result, the relative size of each new variable (compared to the other new variables) should still be reliable.

\section{Results and Discussion}

Some general, descriptive statistical results from the survey are presented in Bergfjord et al. (2011). Some of the main results from the raw data are as follows: We observe that the farmers exhibit a clear, but not extreme risk aversion. The differences between different subsets of the sample are generally small, with the exception that fulltime farmers with high household incomes are less risk averse than others. This is reasonable. These farmers probably are better equipped to take on some risks in order to achieve future gains. Also, some of the difference is probably caused by underlying differences in marital status. Highincome households usually have two incomes, often including one off-farm income, whereas the group with low income to a larger extent consists of oneincome households. This means that the highincome group has a more diversified income base, and thus better opportunities to pursue more risky business strategies.

The focus of this paper is the constructed measures of risk attitude, the information they provide about behavior, and their possible implications. The size, standard errors and 99\% confidence intervals of these new variables are presented in the table below. All variables are significantly different from 0 , and all risk attitude measures are estimated to have absolute values above 0.5 .

Table 2. Descriptive statistic for the risk attitude measures. $\mathrm{N}=514$.

\begin{tabular}{lllll}
\hline Variable $(\mathrm{n}=514)$ & Size & Std error & \multicolumn{2}{l}{$99 \%$ confidence interval } \\
\hline Invest & 1.34 & 0.11 & 1.05 & 1.64 \\
Intense & -0.74 & 0.10 & -0.99 & -0.49 \\
Off_farm & -1.22 & 0.12 & -1.52 & -0.92 \\
Consume & -1.29 & 0.11 & -1.58 & -1.02 \\
Loan & -0.58 & 0.11 & -0.87 & -0.29 \\
Equity & -0.65 & 0.09 & -0.89 & -0.42 \\
Overall & -0.88 & 0.06 & -1.03 & -0.73 \\
\hline
\end{tabular}


All the new variables are negative, except from the first one. This can be interpreted as follows:

1. A gain means more for farm investment than a loss means for farm divestment

2. A gain means less for "extensification" than a loss means for "intensification"

3. A gain means less extra off-farm work than a loss means reduced off-farm work

4. A gain means less extra private consumption than a loss means reduced private consumption

5. A gain means less extra bank savings/reduced loans than a loss means increased loans/reduced savings

6. A gain means less extra investments in shares/equity than a loss means sales of shares/equity

7. A gain generally means less change in behavior than a loss

In general, and as expected, farmers claim that a sudden gain would affect their behavior less than a sudden loss. Although the measure used is not strictly comparable to risk aversion, this is in line with both the risk aversion derived from the raw data in Bergfjord et al. (2011) as well as results from behavioral economics that losses affect behavior more than gains.

We have not found important differences between different subgroups of farmers, for instance based on on- and off-farm income or production types. This is interesting, and indicates that the attitudes found are common for most types of farmers. However, there is a strong correlation between the various constructed variables for each farmer. This means that if a farmer's equity holding is more affected by a loss than a gain, it is likely that also for instance his consumption behavior will be more affected by a loss than a gain. This is also to be expected. Overall, our results are not surprising, in the sense that both moderate risk aversion, larger effect of losses than gains, and generally small differences between different types of farmers in this sample could expected based on theory and earlier work.

Although expected, some further comments regarding the different variables could be useful. For the second variable, about intensification, part of the reason might be the structure of Norwegian agriculture. Many farms are already run rather extensively, and many farmers have other, more important sources of income, almost reducing farming to a hobby. Thus, further "extensification" is difficult and/or pointless, whereas intensification is an option if financial reasons make it necessary.
For our third variable, about off-farm work, there are several potential explanations, in addition to the standard risk aversion component. A related reason is that for less wealthy farmers, increased off-farm income could be a necessity to compensate for a large loss. There are hence good reasons to expect farmers to increase off-farm work in face of a loss, but why do they not reduce off-farm work as much after a gain? One potential reason is the structure of the labor market: If you have an offfarm job, it is often not easy to, say, reduce this from a $100 \%$ to a $50 \%$ position - often the alternative would be to quit the job altogether, which might not be an attractive option. Finally, this can be viewed as a sign that many farmers find their off-farm work rewarding also beyond the financial aspects, and hence would like to work approximately as much as they currently do, even if a financial gain allowed them to work less.

For our fourth variable, about private consumption, we see the same pattern. A potential extra reason for this is that many farmers already have a "sufficiently" high level of private consumption, and expect their consumption to stay more or less the same even if they could afford to spend more.

For our fifth variable, about debt and savings, one additional reason for the negative value could be that farmers have good bank connections and are relatively comfortable with their current debt level, and thus see no urgent need to reduce this. Another reason might be that other options are more attractive than debt payments or bank savings after a sudden gain - for instance farm investments, as indicated by variable 1 .

For our sixth variable, about shares and equity, the variable is again - as expected - negative. An alternative interpretation of this could be low interest in the stock market - alternatively, low expectations about future returns in the stock market.

The one important exception in this picture is farm investment, where a gain apparently means more for investment than a loss means for divestment. Although unexpected based on general theory, we will argue that the result makes sense in this particular setting. Many farming families have off-farm income which is enough to cover most daily expenses. The farm thus is not only a source of profit, but also a home and an instrument for saving. Whatever is left after all the bills are paid is invested in the farm, maybe to generate larger profits from the farm in the future, but also to make 
it a better home, and because it is considered a good investment alternative. This explains one side of the equation - why a sudden gain is perceived to have large impacts on farm investment. The other side of the equation - why a sudden loss would have relatively little impact on farm divestment - is also relatively easy to understand. The extreme effect of farm divestment would be to give up farming. A loss of MNOK 1 is large enough for this to be a real threat for many farmers. If quitting is not necessary, a less drastic farm divestment is likely to be both less convenient and more emotionally painful than, say, a sale of off-farm assets. In a sense, the lifestyle importance of farming is supported by the results from this study: A sudden gain could well be invested in the farm, but to finance a sudden loss, most other options would be preferred rather than farm divestment and a possible new lifestyle as a non-farmer.

\section{Implications}

The results are overall not surprising. The general risk attitude corresponds well to previous studies, and the negative sign of the new «invest» variable is also easy to explain. Nevertheless, we think the results could have some interesting policy implications.

1. Risk management schemes

Farmers are very reluctant to farm divestment and the treat of quitting farming. A reasonable interpretation of this is that the average farmer is able and willing to cope with risk and sudden losses - as long as he is able to handle them without divesting. Hence, it could be proposed that both private (i.e., insurance) and public risk management schemes should be adjusted to account for this. General crop insurance or any similar scheme is likely to be imperfect for most farmers. For relatively wealthy farmers, a bad crop will not force them to divest - they will be able to handle the loss by other means. Hence, insurance could be useful, but it will not be crucial for survival, and self-insurance might be as beneficial in the long run. For some farmers, however, the situation will be the opposite. Standard crop insurance might be useful, but it will typically not eliminate all extra costs associated with a bad crop. For farmers with few off-farm assets, even the (relatively small) losses they have to carry will make it necessary to divest and possibly quit farming. Hence, the insurance scheme will, in some sense, be of little use to them, because a bad crop will force them to give up farming anyway.
2. Policy and general support programs Most developed countries spend large amounts on agricultural subsidies - often through different schemes with different target groups and objectives. Lobley and Potter (2004) recommend a more integrated agricultural policy to take into account the diversity of farmers, including «lifestyle oriented» policies, directed at improving rural living in general, instead of supporting certain types of farm production in particular. Our study supports this recommendation. A reasonable interpretation of the reluctance to divest is that this is based on a strong will to stay on the farm and maintain a farming lifestyle - even if it becomes necessary to cut into other savings or increase the offfarm workload. If more of the support schemes are directed at improving rural living conditions, this would make it easier for many to stay on the farm. Even if their agricultural production is different or smaller than before, and they for instance have to work more offfarm, this is likely to be a good alternative for many farmers.

\section{Conclusions}

Farmers claim that a sudden gain would affect their behavior less than a sudden loss. The main exception is farm investment, which would be more affected by a sudden gain than a sudden loss would affect divestment. This is interesting, as it captures some important aspects of farming lifestyle: A sudden gain is likely to be invested in the farm, but a sudden loss would, if possible, be financed without farm divestment, as this often would lead to giving up farming, or at least some important aspects of the farming lifestyle.

These results are not surprising, as they are in line with both theory and earlier studies. However, the results could have implications for both insurance schemes and general support programs. As most farmers are very reluctant to farm divestment, this treat could be considered more specifically when designing insurance schemes. Also, as maintaining farming lifestyle is considered so important, general support programs could aim at improving rural living in general, rather than supporting specific types of production.

\section{Acknowledgments}

Thanks to the Norwegian Agricultural Economics Research Institute for access to the dataset. Also thanks to Gudbrand Lien and Øyvind Hoveid. Much of the analysis in this paper is based on work on a related paper they co-authored. Of course, the usual disclaimer applies. 


\section{References}

Bergfjord, O. J., G. Lien and Ø. Hoveid. 2011. Factors influencing farmer migration in Norway: a study based on survey results linked to financial data. Food Econ. 8(2):92104.

Bertrand, M., S. Mullainathan and E. Shafir. 2006. Behavioral economics and marketing in aid of decision making among the poor. J. Public Policy Market. 25(1):8-23.

Borges, J. A. R. and J. A. D. Machado. 2012. Risks and Risk Management Mechanisms: An Analysis of the Perceptions of Producers of Agricultural Commodities. Internat. J. Res. Business 2(5):27-39.

Flaten, O., G. Lien, M. Koesling, P. S. Valle and M. Ebbesvik. 2005. Comparing risk perceptions and risk management in organic and conventional dairy farming: empirical results from Norway. Livestock Prod. Sci. 95(1-2):1125.

Hardaker, J. B., R. B. M Huirne, J. R. Anderson and G. Lien. 2004. Coping with risk in agriculture. CABI Publishing, Oxfordshire, UK.

Kahneman, D. and A. Tversky. 1979. Prospect theory: an analysis of decision under risk. Econometrica 47:263-291.

Lien, G., O. Flaten, M. Koesling and A. K. Løes. 2008. Utmelding av norsk øko-bønder - hva er årsakene? Resultater fra en spørreunders $\varnothing$ kelse høsten 2008" [Exits among Norwegian organic farmers - what are the reasons? Results from a survey in fall 2008]. NILF Discussion paper 2008-1, Norwegian Agricultural Economics Research Institute, Oslo. http://www.nilf.no/publikasjoner/ Discussion_Papers/2008/DP-2008-01.pdf
Lobley, M. and C. Potter. 2004. Agricultural change and restructuring: recent evidence from a survey of agricultural households in England. J. Rural Studies 20:499-510.

March, J. G. and Z. Shapira. 1987. Managerial perspectives on risk and risk taking. Manage. Sci. 33:1404-1418.

Moschini, G. and D. A. Hennessy. 2001. Uncertainty, Risk Aversion, and Risk Management for Agricultural Producers. Handbook Econ. 18(1A):87-154.

Pennings, J. M. E. and P. Garcia. 2001. Measuring producers' risk preferences: a global risk attitude measure. Am. J. Agric. Econ. 83:9931009.

Rabin, M. and R. H. Thaler. 2001. Anomalies: risk aversion. J. Econ. Persp. 15:219-232.

Van Raaij, W. F. 1981. Economic psychology. J. Econ. Psychol. 1:1-24. 